\title{
Transition between Suppressed and Active Phases of Intraseasonal Oscillations in the Indo-Pacific Warm Pool
}

\author{
P. A. Agudelo, J. A. Curry, C. D. Hoyos, And P. J. Webster \\ School of Earth and Atmospheric Sciences, Georgia Institute of Technology, Atlanta, Georgia
}

(Manuscript received 15 June 2005, in final form 23 January 2006)

\begin{abstract}
Intraseasonal oscillations (ISOs) are important large-amplitude and large-scale elements of the tropical Indo-Pacific climate with time scales in the 20-60-day period range, during which time they modulate higher-frequency tropical weather. Despite their importance, the ISO is poorly simulated and predicted by numerical models. A joint diagnostic and modeling study of the ISO is conducted, concentrating on the period between the suppressed and active (referred to as the "transition") period that is hypothesized to be the defining stage for the development of the intraseasonal mode and the component that is most poorly simulated.

The diagnostic study uses data from the Tropical Ocean Global Atmosphere Coupled OceanAtmosphere Response Experiment (TOGA COARE). It is found that during the transition period, the ocean and the atmosphere undergo gradual but large-scale and high-amplitude changes, especially the moistening of the lower troposphere caused jointly by the anomalously warm sea surface temperature arising from minimal cloud and low winds during the suppressed phase and the large-scale subsidence that inhibits the formation of locally deep convection. Using a cloud classification scheme based on microwave and infrared satellite data, it is observed that midtop (cloud with a top in the middle troposphere) nonprecipitating clouds are a direct response of the low-level moisture buildup.

To investigate the sensitivity of ISO simulations to the transitional phase, the European Centre for Medium-Range Weather Forecasts (ECMWF) coupled ocean-atmosphere climate model is used. The ECMWF was run serially in predictive ensemble mode (five members) for 30-day periods starting from 1 December 1992 to 30 January 1993, encompassing the ISO occurring in late December. Predictability of the active convective period of the ISO is poor when initialized before the transitional phases of the ISO. However, when initialized with the correct lower-tropospheric moisture field, predictability increases substantially, although the model convective parameterization appears to trigger convection too quickly without allowing an adequate buildup of convective available potential energy during the transition period.
\end{abstract}

\section{Introduction}

The tropical Indo-Pacific warm pool possesses the warmest open-ocean sea surface temperature (SST) and the largest precipitation on the planet. The largescale heating over the tropical warm pools plays a critical role in the global redistribution of heat, moisture, and momentum, resulting in a balancing of the global heat budget (e.g., Webster 1994; Lin and Johnson 1996). The Tropical Ocean Global Atmosphere Coupled Ocean-Atmosphere Response Experiment (TOGA COARE; November 1992-March 1993; Webster and

Corresponding author address: Paula A. Agudelo, School of Earth and Atmospheric Sciences, Georgia Institute of Technology, 311 Ferst Avenue, Atlanta, GA 30332-0340.

E-mail: pagudelo@eas.gatech.edu
Lukas 1992) provided extensive observations of the coupled ocean-atmosphere tropical warm-pool system (Godfrey et al. 1998), leading to an identification of dominant physical processes determining the mean state of the warm pool and its intraseasonal variability (e.g., Godfrey et al. 1998; Zhang 2005).

TOGA COARE provided the first detailed observations of the large-amplitude intraseasonal oscillations [(ISOs) or alternatively Madden-Julian oscillations (MJOs)] of the Indo-Pacific warm-pool evident in lower- and upper-tropospheric winds, cloudiness, precipitation, and surface atmosphere-ocean radiative and turbulent heat fluxes. The ISO comprises a large fraction of the observed tropical variability and is usually manifested as an eastward-propagating planetary-scale convective wave (Madden and Julian 1972, 1994; Hendon and Salby 1994). The ISO is strongest and most 
frequent during the boreal winter and spring, with the propagating convective anomaly originating in the Indian Ocean and weakening as it moves across the Maritime Continent. Reintensification generally occurs in the western Pacific warm-pool region.

Wang et al. (2005) and Stephens et al. (2004) argue that the ISO is an instability of the coupled oceanatmosphere system of the warm pools that is critical for the maintenance of the climatological structure of the tropical warm pools. Stephens et al. (2004) referred to the ISO as a "self-regulating oscillator" and defined a "destabilization" phase that rendered the system amenable for a subsequent "convective" phase. The convective phase was followed by a "restoring" phase where the system stabilizes before entering into another period of destabilization. The period of time needed to destabilize the lower troposphere through the warming of the SST (by enhanced downward solar radiation during the suppressed phase) and the cooling of the upper troposphere (enhanced longwave cooling) determined the time scale of the ISO. Wang et al. (2005) added a spatial aspect to the self-regulating oscillator of Stephens et al. (2004). They noticed that the ascending region of the convective phase of the ISO in the eastern Indian Ocean produced a region of strong subsidence in the western basin, prompting a reduction of cloudiness and a destabilization period similar to the Stephens et al. concept. In this manner one part of the oscillation was producing the next ISO. Wang et al. (2005) referred to this sequence as "self-induction." The two theories are complementary and both point to the transition period between the suppressed and convective stages of the oscillation as critical elements of the ISO. It is important to note that both the selfregulating oscillation and the self-induction theories refer to the coupled ocean-atmosphere system. Indeed, a number of studies have shown that ocean responses to ISO-related atmospheric forcing have also been observed in sea surface temperature, subsurface temperatures, oceanic currents, and the mixed layer depth (e.g., Lukas and Lindstrom 1991; Webster 1994; Zhang and McPhaden 2000; Woolnough et al. 2000; Loschnigg and Webster 2000).

Attempts to simulate the ISO by numerical models have met with difficulties. Inness and Slingo (2003) note that many general circulation models (GCMs) produce some aspects of the ISO but all have problems with determination of the amplitude and the propagation speed and reproduction of the different seasonal aspects. These conclusions were reached after the comparison of ISO characteristics in 15 GCMs as part of the Atmospheric Model Intercomparison Project (AMIP; Slingo et al. 1996). Subsequent studies (Waliser et al. 2003a,b) have found similar model behavior in which models tend to lose the spectral peak associated with the ISO. However, empirical prediction studies (e.g., Webster and Hoyos 2004; Jones et al. 2004) have shown that there is predictability of the ISO with relatively skillful forecasts of regional precipitation and river discharge between 20 and 30 days. Thus, if predictability of the ISO does exist, as demonstrated by the empirical studies, why do models tend to fail even in simulating the ISO?

Possible causes may be the inability of a numerical model to simulate adequately the properties of clouds and their interaction with the lower boundary during the life cycle of the ISO or the interaction of the atmosphere with the upper ocean (e.g., Flatau et al. 1997; Wang and Xie 1998; Waliser et al. 1999). Overall, cloud-related feedback in the climate system in general, and in an ISO in particular, are not well understood (e.g., Stephens et al. 2002). Kikuchi and Takayabu (2004) have classified convection in different stages of the ISO using cloud-top temperatures to define suppressed, developing, mature, and decaying stages. In the present study, we hypothesize that physical processes associated with convection occurring during the transition between the suppressed and active phases are critical to the development of the onset and evolution of the ISO. Specifically, we argue that it is essential that Stephens et al.'s destabilization period be modeled correctly for the appropriate degree of convective available potential energy (CAPE) to be built up in order to allow the correct time scale of the ISO to be modeled. If this does not occur, it is speculated that weak and short period oscillations ensue. To test this hypothesis, a combined diagnostic and coupled ocean-atmosphere modeling study is conducted with a concentration on the transition phase between the suppressed and active periods of convection. We focus on the TOGA COARE period. Section 2 includes analysis of the populations of different types of clouds occurring during the ISO phase transitions as they occurred in TOGA COARE, obtained by using a cloud classification scheme. Section 3 evaluates and interprets the performance of an experimental ensemble simulation using the European Centre for Medium-Range Weather Forecasts (ECWMF) coupled climate model in the transition stages during the IOP. Discussion and conclusions are given in section 4 .

\section{Diagnostics of the transition from suppressed to active convection}

We use observations from TOGA COARE (Webster and Lukas 1992) to clarify processes occurring during 
the transition from suppressed to active convection for the two ISOs that occurred during this period and to present analyses that will be used in the following section to be compared with the model simulations. The observational network of TOGA COARE consisted of three spatially overlapping observational arrays: the large-scale array (LSA), outer sounding array (OSA), and intensive flux array (IFA) centered at $2^{\circ} \mathrm{S}, 156^{\circ} \mathrm{E}$. Background in situ measurements and satellite observations measured the state of the large-scale environment. The interactions between the larger-scale circulation of the atmosphere and ocean were measured by the LSA. Mesoscale circulations associated with convection in the atmosphere were resolved by the OSA and the IFA. A survey of preliminary results from TOGA COARE is given in Godfrey et al. (1998). A brief overview of the ISO cycle is presented in the next section, followed by a detailed analysis of the transition from suppressed to convective stages of the ISO.

\section{a. General features observed during TOGA COARE}

\section{1) DYNAMICS AND THERMODYNAMICS}

Previous studies (e.g., Gutzler et al. 1994; Weller and Anderson 1996; Lau and Sui 1997; Godfrey et al. 1998) have identified two eastward-propagating ISO events in the TOGA COARE intensive observing period (IOP) (Fig. 1) with intensified rainfall over the IFA during the last 2 weeks of December 1992 and between late January and early February 1993 (Fig. 2a). The ISO signal in outgoing longwave radiation (OLR; data from Liebmann and Smith 1996) is evident in Fig. 2b with negative and positive values indicating enhanced convection and its absence, respectively. Collectively, Figs. 1 and 2 show that the two ISOs occurring during TOGA COARE possessed time scales similar to other ISOs (Wheeler and Kiladis 1999; Zhang 2005) and that both suppressed and active convection phases of the ISOs are large-scale features. Figure $2 b$ shows the dates selected based on the filtered OLR time series corresponding to the suppressed, transition, and active phases of convection during the first ISO event. Although an exact definition of a transition is elusive because of the large degree of intermittency in the atmosphere, the intraseasonal signal within the OLR fields are used as a proxy to define the timing of the transition stage during the TOGA COARE IOP. Two such transitions during the IOP were isolated as periods enclosed between a maximum and a subsequent minimum in the intraseasonal OLR time series.

Soundings over the IFA and the LSA provide detailed information on the vertical structure of the at-

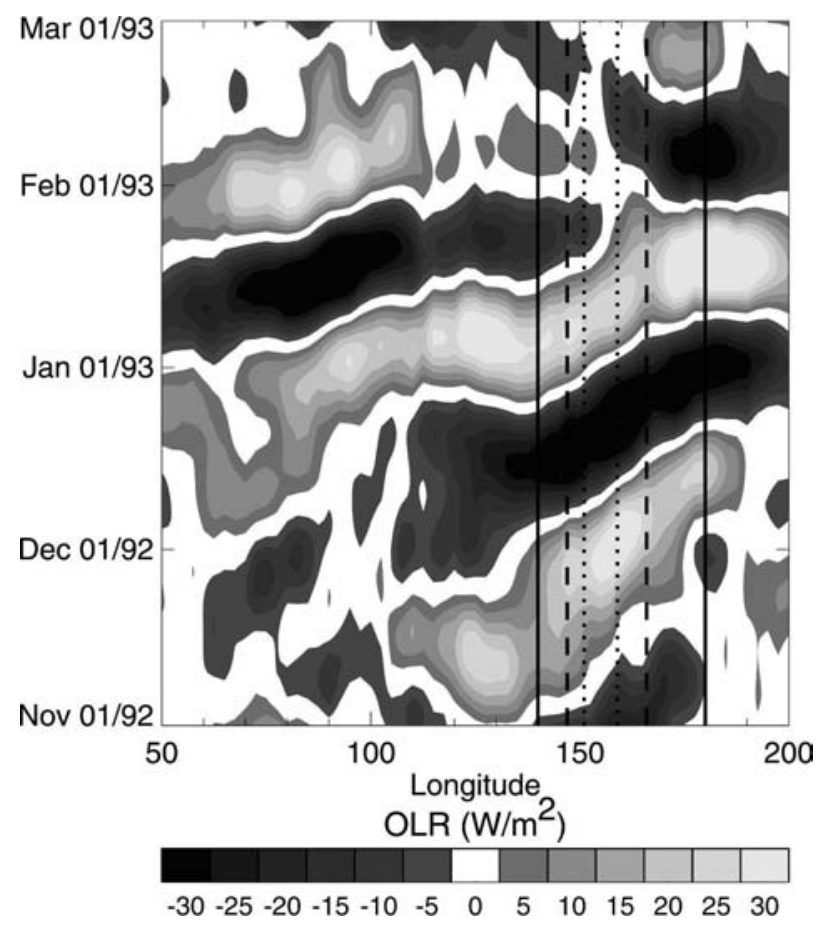

FIG. 1. Longitude-time diagram of average OLR during the IOP for latitudes between $10^{\circ} \mathrm{S}$ and $10^{\circ} \mathrm{N}$ showing two eastwardpropagating ISO events. Lines represent the domains of the TOGA COARE IOP: the LSA (solid lines), OSA (dashed lines), and IFA (dotted lines).

mosphere during the IOP. Version 2.1 of the IFAaveraged fields and the LSA gridded dataset by Ciesielski et al. (2003) were used in this study. Both datasets were prepared using the humidity-corrected radiosonde data by Wang et al. (2002). Table 1 shows the anomalies in the SST, the lower-tropospheric zonal wind component, and the OLR, relative to the means for the IOP for three phases of the ISO-suppressed, transitional, and convective. It is clear that the major variability of these variables occur on intraseasonal time scales: weak easterlies, a dry and cool middle and upper troposphere characterize the suppressed periods; and strong deep westerlies, a moist middle and upper troposphere and a relatively warm upper troposphere characterize the convective periods.

\section{2) SST AND HEAT FLUXES}

Two marked warming phases with maximum SST occurred at the beginning of December 1992 and in midJanuary 1993, leading the enhanced convection seen in Fig. 2 by about approximately a week (see Table 1). These positive SST anomalies were followed by a marked cooling, which is especially intense after the first event (late December and early January). In addi- 
a) Rainfall Rate ( $\mathrm{mm} / \mathrm{hr}$ )

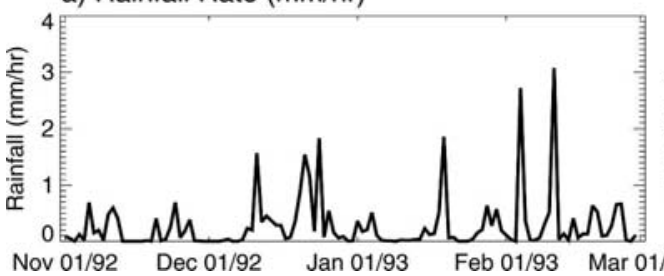

b) $\operatorname{OLR}\left(\mathrm{W} / \mathrm{m}^{2}\right)$

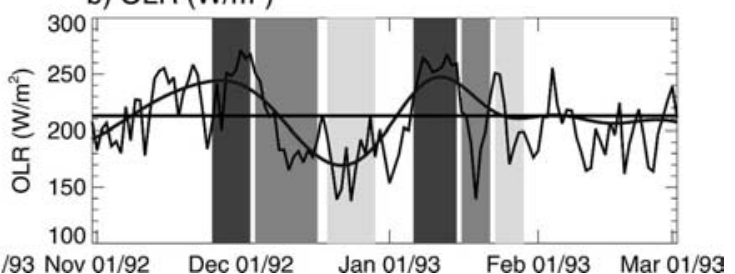

FIG. 2. (a) SSM/I (Hollinger et al. 1990) rainfall $\left(\mathrm{mm} \mathrm{h}^{-1}\right)$ time series during the IOP over a region enclosing the IFA $\left(4^{\circ} \mathrm{S}-2^{\circ} \mathrm{N}, 150^{\circ}-160^{\circ} \mathrm{E}\right)$, and (b) OLR time series during the IOP over the IFA. Horizontal line represents the mean OLR during the IOP. The smooth line represents the OLR in the intraseasonal band. The suppressed (dark gray; 25 Nov-3 Dec 1992 and 6-15 Jan 2003), transition (gray; 4-17 Dec 1992 and 16-22 Jan 2003), and active (light gray; 19-29 Dec 1992 and 23-29 Jan 2003) phases of the ISO events during the IOP over the IFA.

tion, the amplitude of the diurnal variation is severely modulated by the ISO. This is due to the lack of clouds during the suppressed phase, indicating that the intraseasonal activity modulates the amplitude of the SST diurnal cycle. This warming accompanies an increase in ocean heat storage.

During the ISO there is a reversal of wind direction in surface winds between the suppressed (weak easterlies), transitional (weak westerlies), and active (strong westerlies) periods (Table 1). These low-level westerlies, referred to as westerly wind bursts (Lukas and Lindstrom 1991), were especially strong during late December, reaching maximum values of $14 \mathrm{~m} \mathrm{~s}^{-1}$ at the surface. The improved meteorological surface mooring (IMET) buoy located off the equator also showed changes in the surface meridional wind, with strong northerlies during the convective phase, which were probably associated with the thermally forced Rossby wave component (e.g., Gill 1980).

Associated with the ISO are large-amplitude perturbations in surface net heat flux that play an important role in modifying both the atmosphere and ocean. Using data from the IMET buoy (Weller and Anderson 1996), Table 1 describes the heat flux components dur- ing the different phases of the ISO, with positive values indicating a warming of the ocean. During the undisturbed periods, strong solar radiation and weak winds (low latent heat flux) produce a net heating of the ocean. During disturbed phases, the strong winds and reduced insolation contribute to a net cooling of the ocean. The average value of surface net heat flux during the marked suppressed phase from 5 to 15 January 1993 was $+83 \mathrm{~W} \mathrm{~m}^{-2}$. In contrast, during the prior convective phase (20-30 December 1992) the net heat flux was $-65 \mathrm{~W} \mathrm{~m}^{-2}$. These variations are comparable to those found for ISOs in other regions of the IndoPacific warm pool (Webster et al. 2002). During the suppressed (convective) phase, the average contribution to the warming (cooling), relative to the IOP mean, of the net shortwave radiation and the latent heat flux are about $+17(-50)$ and $+57(-15) \mathrm{W} \mathrm{m}^{-2}$, respectively.

\section{3) EVOlution of CLOUd FIELDS}

Johnson et al. (1999) showed that three cloud typescumulus, cumulus congestus, and cumulonimbus-are important components of the tropical convective cloud spectrum, and that these three cloud populations vary

TABLE 1. Average values during the IOP, and during suppressed, transition, and active phases relative to the IOP mean.

\begin{tabular}{lrrrr}
\hline \hline \multirow{2}{*}{\multicolumn{1}{c}{ Variable }} & \multicolumn{3}{c}{ Phases } \\
\cline { 2 - 5 } & \multicolumn{1}{c}{ IOP } & Suppressed $^{\mathrm{a}}$ & Transition $^{\mathrm{b}}$ & Active $^{\mathrm{c}}$ \\
\hline SST $\left({ }^{\circ} \mathrm{C}\right)$ & 29.4 & $0.42(0.31)$ & 0.43 & -0.32 \\
Zonal wind $\left(\mathrm{m} \mathrm{s}^{-1}\right)$ & 1.8 & $-0.54(-1.81)$ & 0.34 & 3.2 \\
OLR $\left(\mathrm{W} \mathrm{m}^{-2}\right)$ & 213.1 & $31.9(36.9)$ & -15.9 & -39.4 \\
Net heat flux $\left(\mathrm{W} \mathrm{m}^{-2}\right)$ & 3.3 & $67.4(83.1)$ & 8.0 & -65.0 \\
Net shortwave radiation $\left(\mathrm{W} \mathrm{m}^{-2}\right)$ & 191.3 & $42.6(17.4)$ & 3.2 & -50.1 \\
Latent heat flux $\left(\mathrm{Wm}^{-2}\right)$ & -115.7 & $32.3(57.2)$ & 10.1 & -15.4 \\
Specific humidity $900-200 \mathrm{mb}\left(\mathrm{g} \mathrm{kg}^{-1}\right)$ & 5.4 & $-0.22(-0.14)$ & 0.23 & 0.50 \\
\hline
\end{tabular}

a From 25 Nov to 3 Dec 1992 (from 5 to 15 Jan 1993).

${ }^{\mathrm{b}}$ From 4 to 17 Dec 1992.

${ }^{\text {c }}$ From 19 to 29 Dec 1992. 


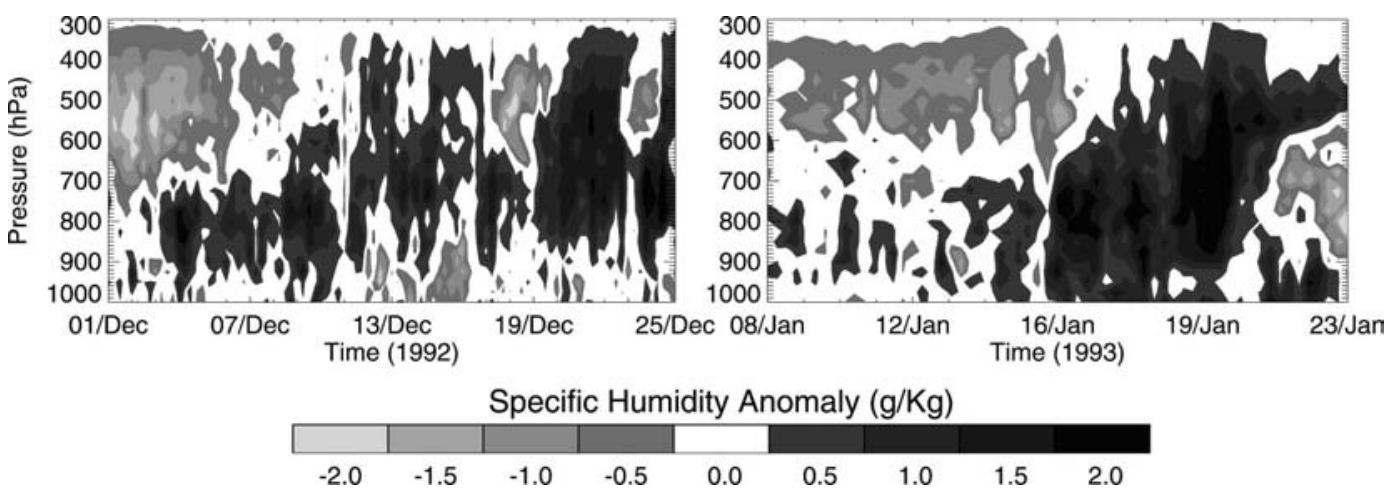

FIG. 3. Vertical distribution of specific humidity anomalies over the IFA for both transition periods observed during the IOP computed for each level relative to the mean value for the whole period. Low-level moistening is evident before deep convection takes place.

substantially with a time scale of 30-60 days. In a complementary analysis, Wang et al. (2005) analyzed cloud variations during the summer ISO in terms of cloud-top temperature.

To examine the impact of clouds on the evolution of the ISO more comprehensively than previous studies (e.g., Johnson et al. 1999; Wang et al. 2005), we use the satellite-derived cloud classification scheme of Liu et al. (1995) that combines satellite microwave and infrared data. Infrared data are used to determine cloud-top temperature, and microwave data are used to determine an index that includes both microwave scattering and emission. The microwave index $(f)$ represents the strength of the microwave signal from a cloudy pixel, and it is a good indicator for rainfall rate and dense ice. Here, the cloud-top temperature from Geostationary Meteorological Satellite (GMS)-4 and the microwave index computed using the Special Sensor Microwave Imager (SSM/I) during TOGA COARE IOP are used. Liu et al. (1995) noted that in general, the classification shows good agreement with radar observations for large cloud systems, which is able to distinguish between precipitating and nonprecipitating clouds. However, the scheme has shown difficulties in resolving the small, isolated clouds because of the relatively coarse resolution of the SSM/I data. Also, the determination of threshold values for $f$ and its dependence on dense ice amounts, which is difficult to measure, introduces uncertainty in the separation among high, precipitating clouds.

Using the Liu et al. (1995) scheme, clouds were classified into the following eight classes: warm nonprecipitating cloud, warm precipitating cloud, midtop nonprecipitating cloud, midtop precipitating cloud, thin high-top nonprecipitating cloud, deep high-top nonprecipitating cloud, anvil with stratiform precipitating cloud, and deep convective precipitating cloud. Here the term "midtop" refers to clouds with tops in the middle troposphere. Over the entire IOP, $21 \%$ of the pixels were classified as clear and just $14 \%$ of the pixels were associated with precipitating clouds. The most abundant species are warm nonprecipitating cloud (31\%). Precipitating warm clouds make up only $1 \%$ of pixels. Midtop clouds account for $36 \%$, most of which are nonprecipitating. High top occupy $13 \%$ of the pixels on average of which nearly all are precipitating.

We now consider the cloud populations during suppressed and convective periods and the transition period from suppressed to convective (Table 2). The amount of cloud-free pixels clearly changes from the suppressed $(52 \%)$ to the convective $(8 \%)$ phase. During the suppressed phase, cloud-free pixels comprise about $60 \%$ of all pixels, while during the last 2 weeks of December, a large-scale deep convective stage, cloudfree pixels were only about $8 \%$ of the total pixels. Precipitating clouds increase from $4 \%$ during the suppressed phase to $16 \%$ during the transitional phase and $30 \%$ during the convective phase. This increase over the lifetime of an ISO is due mainly to high-top convective clouds. Warm nonprecipitating clouds, the dominant cloud type throughout the IOP, are a maximum during the suppressed and transitional periods (31\% and $33 \%$, respectively), dropping off by almost a factor of 2 during the convective period (20\%). Midtop nonprecipitating clouds, on the other hand, increase by more than a factor of 2between the suppressed (12\%) and transitional periods $(28 \%)$.

\section{b. Transition phases during TOGA COARE}

The dominant feature of the transition is the organized low-level atmospheric moistening noted in Fig. 3. Figure 3 shows details of the moisture buildup within the IFA during both transition stages, with moistening gradually extending to the upper troposphere. During 
a) Specific Humidity Anomalies
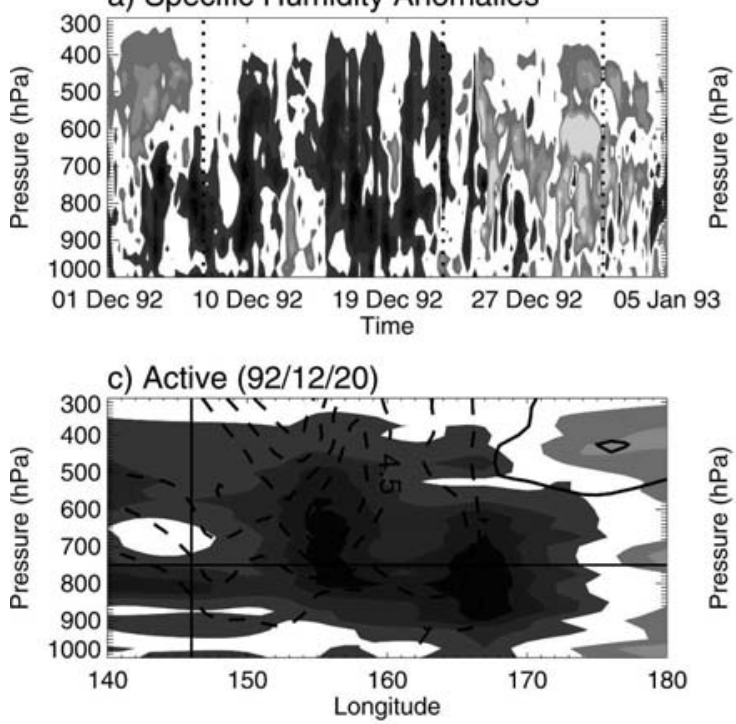

b) Transition (92/12/07)
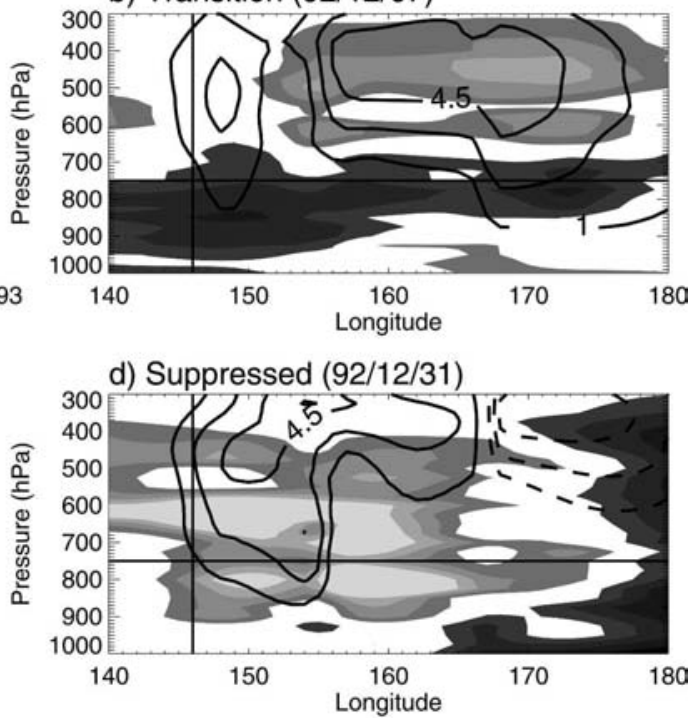

Specific Humidity Anomaly $(\mathrm{g} / \mathrm{Kg})$

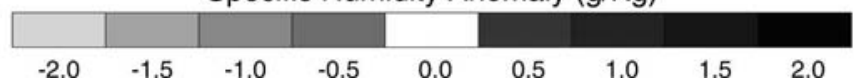

FIG. 4. (a) Vertical distribution of specific humidity anomalies over $0^{\circ}, 146^{\circ} \mathrm{E}$ during the IOP. Anomalies are computed for each level relative to the IOP mean value. Specific humidity anomalies along the equator from $140^{\circ} \mathrm{E}$ to $180^{\circ}$ for (b) transition, (c) active, and (d) suppressed conditions [vertical dotted lines in (a)]. Black contours represent vertical velocity $\omega\left(\mathrm{hPa} \mathrm{h}^{-1}\right)$. Solid contours indicate air subsidence and dashed contours indicate convection.

the second transition period the moisture appears to accumulate more quickly.

Various studies have suggested that the upward transport of water from the boundary layer into the free troposphere might precondition the atmosphere for deep convection (Hendon and Salby 1994; Maloney and Hartmann 1998; Kemball-Cook and Weare 2001; Stephens et al. 2004). The observed low-level moistening noted here is associated with anomalously warmer SSTs during the suppressed and transitional period and increasing low-level winds throughout the transitional period, both of which enhance evaporation (Table 1). However, without a suitable large-scale circulation pattern, the instability of the vertical will rapidly be rectified and large values of CAPE, which are necessary to fuel the convective stage, will not materialize. Figure $4 \mathrm{a}$, constructed using the LSA sounding data, shows the vertical distribution of specific humidity anomalies at $0^{\circ}, 146^{\circ} \mathrm{E}$ (located to the west of the IFA) for the first ISO event. Low-level moistening is apparent through the transitional period prior to the advent of deep convection in a similar fashion as observed within IFA, indicating that the moistening is a common feature for the region. Figures $4 \mathrm{~b}-\mathrm{d}$ show longitude-pressure sections along the equator at key stages of the first ISO. Figure $4 \mathrm{~b}$, depicting the first transitional period, shows significant moistening of the atmosphere below $700 \mathrm{hPa}$ while, simultaneously, the upper troposphere is drier than the IOP average. Atmospheric subsidence (solid black contours) above $800 \mathrm{hPa}$ appears as a key factor inhibiting the deep moistening of the atmosphere. Thus, the combination of enhanced evaporation resulting from stronger low-level winds and warmer SST and large-scale subsidence results in the organized moisture buildup of the lower troposphere. On the other hand, during the deep convective phase, positive anomalies of moisture extend throughout the tropopause accompanied by ascending air (Fig. 4c). During periods of suppressed convection and strong subsidence (Fig. 4d), the entire atmospheric column appears anomalously dry. Similar features are observed for the second transitional period (Figs. 5a-d).

The processes occurring during the transition phase help destabilize the atmosphere and are associated with increasing values of the CAPE. On the other hand, processes associated with the active phase lead to an increasing atmospheric stability and a corresponding decrease of CAPE. Figure 6 shows the buildup of CAPE during the suppressed period and the first half of the unstable transition stage and the rapid reduction of CAPE during the convective phase of the ISO. During the transition, deep convection is inhibited by 
a) Specific Humidity Anomalies

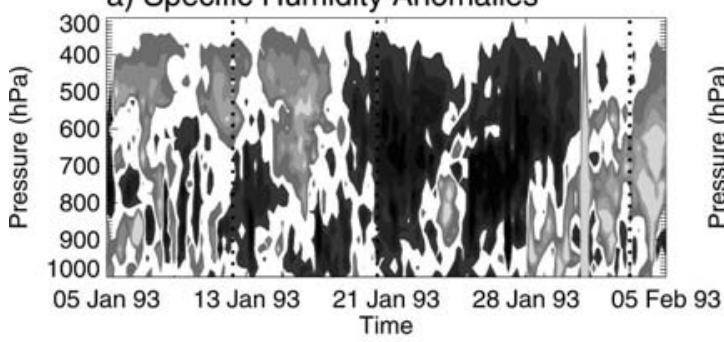

c) Active (93/01/20)

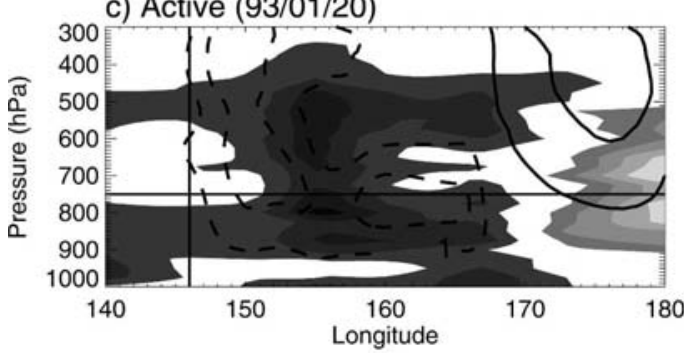

Specific Humidity Anomaly $(\mathrm{g} / \mathrm{Kg})$ b) Transition (93/01/12)
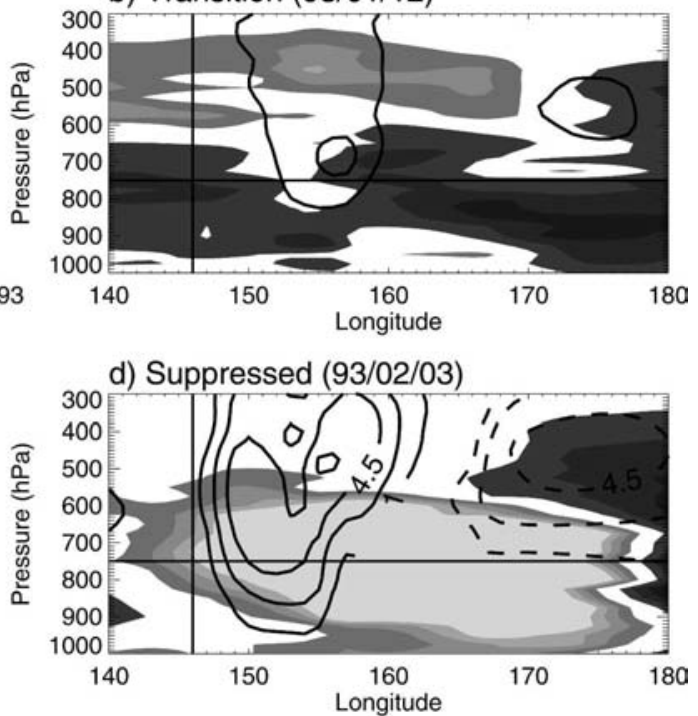

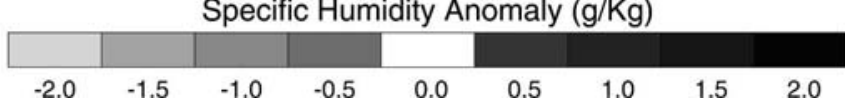

FIG. 5. Same as Fig. 4, but for the second ISO during the IOP.

subsidence. This phenomenon favors the organization of large-scale, low-level moistening, preconditioning the atmosphere for the following deep convection event.

In general, moistening the middle troposphere leads to cloud formation. The reduction of cloud-free pixels is evident in both transition stages, together with the slow increase in midtop nonprecipitating clouds (Table 2). Lin and Johnson (1996) speculated that the lowlevel moistening might be a consequence of vigorous boundary layer mixing and shallow nonprecipitating cumulus clouds during these high-wind periods. Our analysis shows, however, that warm (i.e., shallow) nonprecipitating clouds tend to be constant through the suppressed and transitional periods and are arguably independent of the moistening of the boundary layer (Table 2). This latter observation is consistent with a more recent analysis of Lin and Johnson (1996). On the other hand, the rapid increase of midtop nonprecipitating clouds between the suppressed (12\%), transitional

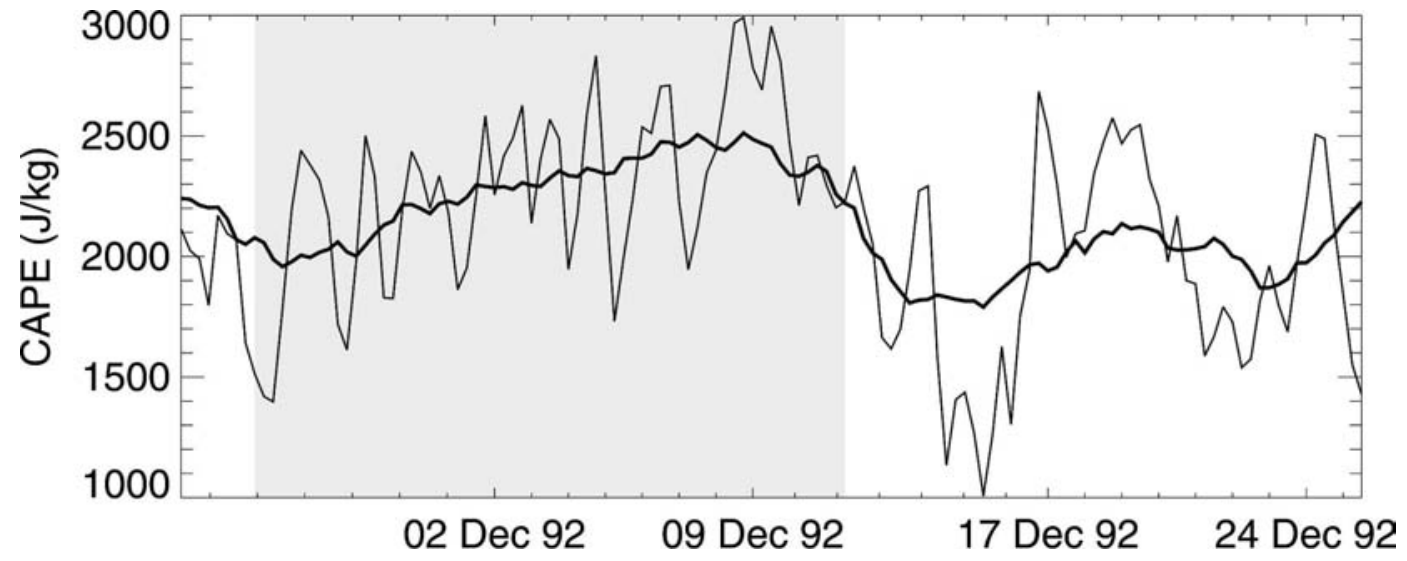

FIG. 6. 12-h CAPE estimates from soundings over the IFA for the first transition period during the IOP. The shadowed area highlights the slow building up of CAPE during the suppressed and transition phases of the first ISO during the IOP. 
TABLE 2. Percentage of cloud types within the IFA during the IOP, and during suppressed, transition, and active phases.

\begin{tabular}{|c|c|c|c|c|}
\hline \multirow[b]{2}{*}{ Cloud type } & \multicolumn{4}{|c|}{ Phases } \\
\hline & IOP & Suppressed & Transition & Active \\
\hline Warm nonprecipitating & 31 & 31 & 33 & 20 \\
\hline Warm precipitating & 1 & 0.2 & 1 & 1 \\
\hline Midtop nonprecipitating & 30 & 12 & 28 & 35 \\
\hline Midtop precipitating & 6 & 2 & 5 & 10 \\
\hline Thin high-top nonprecipitating & 0.4 & 0.1 & 0.2 & 1 \\
\hline Deep high-top nonprecipitating & 4 & 1 & 4 & 7 \\
\hline Anvil with stratiform precipitating & 7 & 2 & 9 & 17 \\
\hline Deep convective precipitating & 1 & 0.1 & 1 & 3 \\
\hline Clear sky & 21 & 52 & 18 & 8 \\
\hline Total precipitating clouds & 14 & 4 & 16 & 30 \\
\hline Total nonprecipitating & 62 & 43 & 61 & 56 \\
\hline Total warm & 32 & 31 & 34 & 21 \\
\hline Total midtop & 36 & 14 & 33 & 45 \\
\hline Total high & 13 & 3 & 15 & 28 \\
\hline
\end{tabular}

$(28 \%)$, and convective $(35 \%)$ phases indicate a close association with the ISO.

\section{Numerical modeling of the TOGA COARE ISOs}

Here we use the analysis for TOGA COARE to help understand the problems that numerical models have in simulating the ISO. Toward this end, we analyze experimental ocean-atmosphere coupled model simulations made for the TOGA COARE IOP following the ECMWF monthly forecasting framework (Vitart 2004). The atmospheric component has a resolution of $1.9^{\circ} \times$ $1.9^{\circ}$ (TL95) with 40 levels in the vertical. The oceanic component is Hamburg Ocean Primitive Equation (HOPE) from the Max Planck Institute and it has a zonal resolution of $1.4^{\circ}$ and 29 vertical levels (Wolff et al. 1997). The coupling of the components is trough the interface Ocean Atmosphere Sea Ice Soil (OASIS) developed at the Centre Européen de Recherche et Formation Avancée en Calcul Scientifique (CERFACS) (Terray et al. 1995).
Initial conditions for the atmospheric and land surface were obtained from the ECMWF operational atmospheric analysis/reanalysis system [ECMWF 40-yr Re-Analysis (ERA-40); Simmons and Gibson 2000]. The oceanic data assimilation system used to produce the initial conditions of the ECMWF seasonal forecasting system was used to generate initial conditions for the oceanic component. Figure 7a shows a time-pressure diagram of specific humidity anomalies from ERA-40 from 5 to 30 December 1992. Anomalies are computed for each level relative to the mean ERA-40 value from 1 November 1992 to 28 February 1993 in the same way that the anomalies were determined in section 3. By comparing Figs. 3a and 7a, it is seen that, even with a lower vertical resolution in the vertical compared to the IFA measurements, ERA-40 data, used in initializing the simulations, capture the characteristics of the lowlevel moistening of the atmosphere.

The period selected for the analysis of the model output corresponds to the transition phase of both ISO events observed during the TOGA COARE IOP. The experimental design was aimed at investigating the pre-

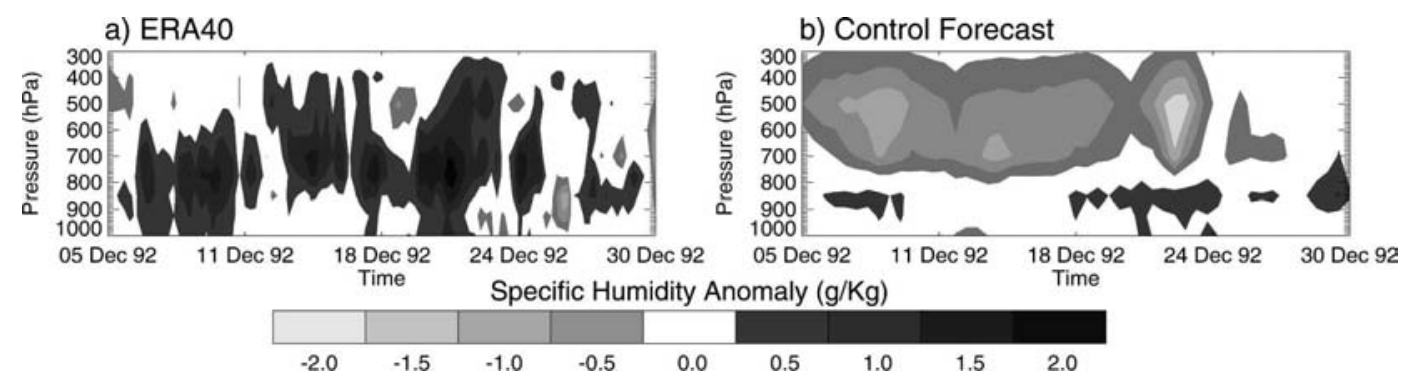

FIG. 7. Time-pressure diagram of specific humidity anomalies over IFA from (a) ERA-40 and (b) the control run initialized on 5 Dec 1992. Given the "dry" initialization, no ensemble skillfully reproduces the observed data. 


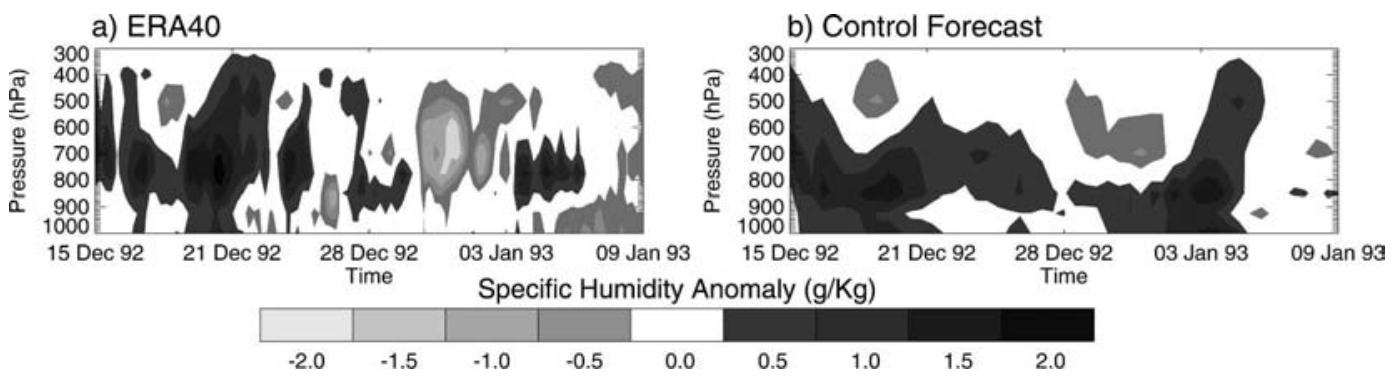

FIG. 8. Same as Fig. 7, but initialized on 15 Dec 1992. When the moistening is part of the initial conditions, all ensemble members reproduce better the observations for the first 7 days of the forecast.

diction of the ISO with initialization before, during, and after the maximum intensity of the oscillation. A major recommendation emerging from the ECMWF-Climate Variability and Predictability Study (CLIVAR) intraseasonal variability workshop (see information online at http://www.ecmwf.int/newsevents/meetings/ workshops/2003/Intra-seasonal_variability/) was to perform a series of extended forecasting simulations using the ECMWF coupled monthly forecast system in order to evaluate the ability of the model to reproduce the observations in different phases of the ISO for welldocumented events. One of the selected events corresponds to the TOGA COARE IOP. A series of integrations of 30-day duration using the ECMWF coupled model were performed. Integrations started about 20 days prior to the maximum convective activity associated to the ISO in the western Pacific Ocean. The integrations are reinitialized each successive day for a 40-day period, including five ensemble members for each the initialization days. The experiment, which runs through all of the stages of the ISO, allows for discerning why, where, and when the ECMWF model loses skill in forecasting intraseasonal activity. Because the general results from both transition periods are similar, only simulations for the first event are discussed here. Results of two integrations, one starting 5 December (Fig. 7), just before the observed low-level moisture build up, and the other starting 15 December (Fig. 8), after the low-level moisture has been observed to occur (and was included in initialization), summarize the general skill of the model in simulating the low-level moistening during the transition period.

Figure $7 \mathrm{~b}$ shows a time-pressure diagram of specific humidity anomalies relative to the mean ERA-40 values over the IFA region during IOP for the control forecast. Each ensemble member was very similar to the control forecast, and there was little divergence between them. None of the five ensemble members reproduce the general character of the IOP observations (Fig. 3a) or the ERA-40 dataset (Fig. 7a). While moist- ening and deep convection are absent in all of the runs, an anomalously dry upper troposphere is formed by each simulation in each of the ensembles maintaining the negative anomalies of midtropospheric specific humidity present in the initial conditions at 5 December. Model results of the 15 December run (Figs. 8b) show improvement for the first 5-7 days of the forecast in all ensemble members. In this case, with the atmosphere initialized to be already moist, the model was able to sustain the anomaly although deep convection did not form.

In summary, all runs from 1 to 20 December show similar results: the model was not able to develop moistening when it was not already present in the initial conditions and maintained an overly dry upper troposphere. However, when the initial conditions contained positive anomalies of specific humidity, forecasts were improved considerably for the first week. To summarize, the model was not able to forecast the moistening of the middle troposphere through the transition stage. Because observations indicate that the low-level moistening during the transition is an integral and important part of the ISO, this failing is potentially one of the obstacles hindering extended forecasts of intraseasonal activity using numerical models.

Figures 9 and 10 show the zonal wind anomalies relative to the mean ERA-40 values during IOP for the reanalysis and the ensemble mean starting on 5 and 15 December, respectively. The results of these two runs summarize the general findings of the forecasts during both transition periods of the IOP. Regardless of the ISO phase, the skill of the model forecasting zonal winds and, in general, all dynamical fields appear to be higher than the skill for physical fields as portrayed in Figs. 7 and 8 for the specific humidity. Even though model skill increases for zonal winds, capturing the reversal of the winds associated with the ISO event reasonably well, the magnitude of the forecasted winds is only a third of that observed during IOP (Table 1) and in the ERA-40 dataset (Figs. 9a and 10a). As shown in 


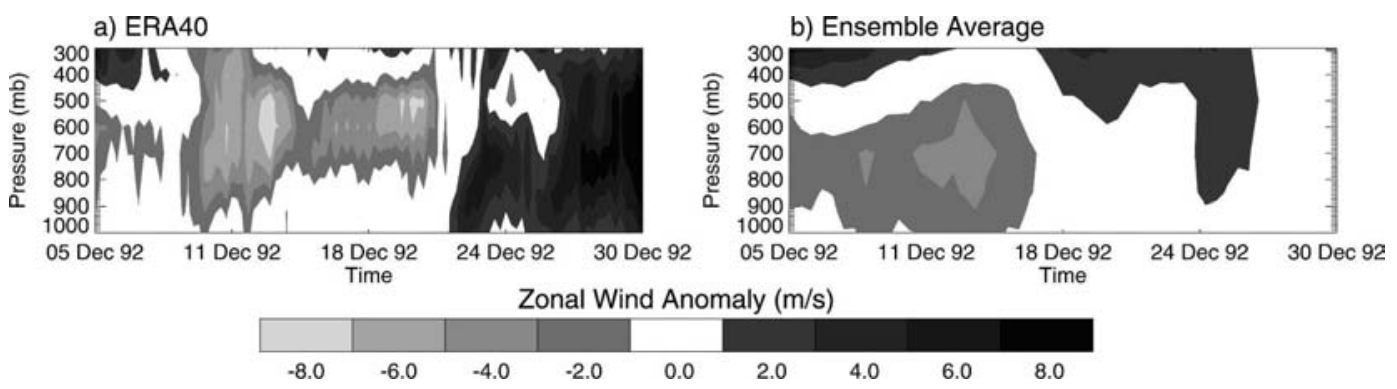

FIG. 9. Time-pressure diagram of zonal wind anomalies over IFA from (a) ERA-40 and (b) the five-ensemble member average initialized using 5 Dec 2002 ERA-40 data.

Figs. 9 and 10, the underestimation of the wind magnitude is greatest in the runs where the low-level moistening is not present in the initial conditions.

When results from the model for variables like surface latent heat flux and top-of-the-atmosphere thermal radiation (Fig. 11) are compared with observed and reanalysis data, important differences are evident, once again, for the runs starting on 5 December. In the case of the latent heat fluxes, differences over $20 \mathrm{~W} \mathrm{~m}^{-2}$ are shown (Fig. 11a) for all of the ensemble members even during the first days of the integration, resulting in less water vapor input into the lower troposphere. For the run starting on 15 December the model of the surface latent heat flux is very close to the observations especially for the first 8 days of integration. For the top-ofthe-atmosphere thermal radiation (OLR; Fig. 11b), both integrations show poor skill. In particular, the 5 December run shows discrepancies over $100 \mathrm{~W} \mathrm{~m}^{-2}$ during the first week of the integration.

As a final diagnostic, CAPE was estimated from ERA-40 and model results (Fig. 12b) show how both the amplitude and the variability of ERA-40 and the model are much smaller than the ones presented in Fig. 6. The CAPE analysis illustrates once again the model problems in accurately representing important convection-related variables.

\section{Conclusions}

We have hypothesized that physical processes associated with atmospheric humidity occurring during the

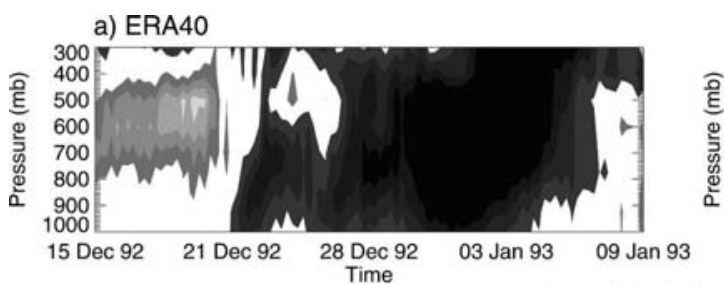

Zonal Wind Anomaly $(\mathrm{m} / \mathrm{s})$ transition between the suppressed and active phases are critical to the development of the onset and evolution of the ISO. To test this hypothesis, a combined diagnostic and coupled ocean-atmosphere modeling study was conducted with a concentration on the transition phase between the suppressed and active periods of convection, focusing on the TOGA COARE period.

This study has provided a synthesis of observations of the two ISOs occurring during the TOGA COARE IOP that clarifies the role of clouds, moisture, and convection during the ISO transition through the application of a satellite-based cloud classification scheme that includes information on precipitation types as well as cloud-top temperature/height. During the transition between suppressed and active phases, organized lowlevel moistening appears as the most important feature foreshadowing the deep convection. CAPE also builds up during the suppressed and transition phase. A combination of anomalously warm SST (and ocean mixed layer) and strengthening low-level winds, together with large-scale subsidence promotes low-level moisture accumulation. Large-scale subsidence plays a very important role because it inhibits local development of deep convection from positive anomalies of low-level humidity, hence favoring the moisture buildup. As a result of the moistening, there is a reduction of cloud-free areas and formation of midtop nonprecipitating clouds during the transition phase. Warm (shallow) nonprecipitating clouds do not appear to be directly linked to ISO. Once deep convection is initiated, intense precipitation

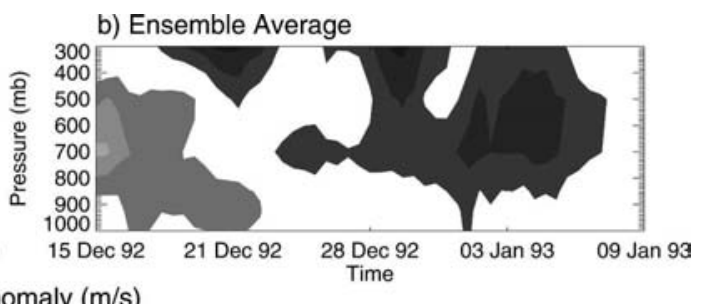

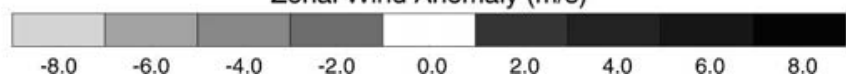

FIG. 10. Same as Fig. 9, but initialized on 15 Dec 1992. 

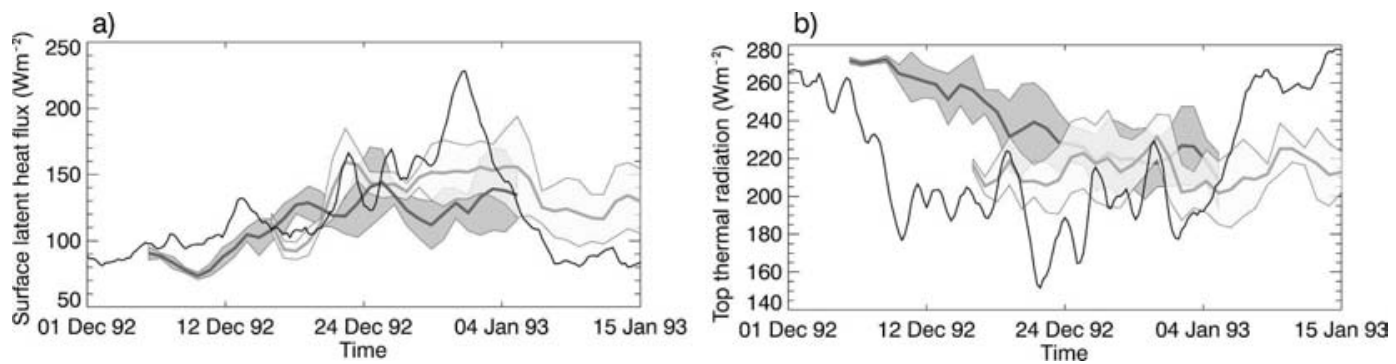

FIG. 11. Forecasts of (a) surface latent heat flux $\left(\mathrm{W} \mathrm{m}^{-2}\right)$ and (b) top-of-the-atmosphere thermal radiation $\left(\mathrm{W} \mathrm{m}^{-2}\right.$ ) initialized on 5 (dark-gray line) and 15 (light-gray line) Dec 1992. The shadowed area represents the spread of the five ensemble members (plus and minus one standard deviation). The black line corresponds to the ERA-40 values.

and upper-tropospheric warming resulting from latent heat release is observed. Westerly winds reach maximum strength during or short after the maximum convection.

We showed that the ECMWF coupled model was not able to reproduce, even in the short term, the observed moisture buildup associated with ISOs during TOGA COARE. The model was unable to develop the lowlevel moistening of the atmosphere if those conditions are not already part of the initial conditions. In addition, the observed CAPE buildup prior to the convective stage was absent in the model simulations. Predictability of the active convective period of the ISO is poor when initialized before the transitional phases of the ISO. However, when initialized with the correct lowertropospheric moisture field, predictability increases substantially, although the model convective parameterization appears to trigger convection too quickly without allowing an adequate buildup of convective available potential energy during the transition period. Overall, the analysis suggests deficiencies in parameterizations of convection and air-sea interactions. In addition, the model appears to produce subsidence that is too weak or a cloud parameterization that is insensitive to subsidence. In summary, the analysis of the ECMWF runs points out toward model inadequacies that, if corrected, could lead to improved simulations and predictions of the ISO.

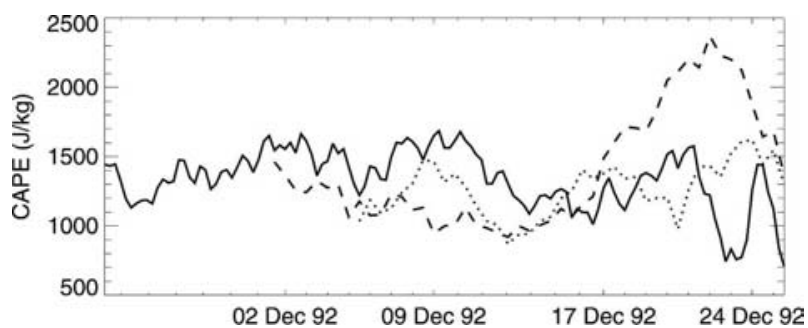

FIG. 12. Same as Fig. 6, but for ERA-40 (solid line); the control run initialized 1 (dashed line) and 5 (dotted line) Dec 1992.
Acknowledgments. This research has been supported by grants from the National Science Foundation's Atmospheric Division under NSF Grant 0531771 (PJW) and a DOE ARM Grant 3506b42 (JAC). ERA-40 data used in this study were obtained from the ECMWF data server. We would particularly like to acknowledge Frederic Vitart, Steven Woolnough, Tim Palmer, and Martin Miller for making the serial integrations of the ECMWF model available for analysis.

\section{REFERENCES}

Ciesielski, P. E., R. H. Johnson, P. T. Haertel, and J. Wang, 2003: Corrected TOGA COARE sounding humidity data: Impact on diagnosed properties of convection and climate over the warm pool. J. Climate, 16, 2370-2384.

Flatau, M., P. J. Flatau, P. Phoebus, and P. P. Niiler, 1997: The feedback between equatorial convection and local radiative and evaporative processes: The implications for intraseasonal oscillations. J. Atmos. Sci., 54, 2373-2386.

Gill, A. E., 1980: Some simple solutions for heat-induced tropical circulation. Quart. J. Roy. Meteor. Soc., 106, 447-462.

Godfrey, J. S., R. A. Houze, R. H. Johnson, R. Lukas, J.-L. Redelsperger, A. Sumi, and R. Weller, 1998: Coupled OceanAtmosphere Response Experiment (COARE): An interim report. J. Geophys. Res., 103, 14 395-14 450.

Gutzler, D. S., G. N. Kiladis, G. A. Meehl, K. M. Weickmann, and M. Wheeler, 1994: The global climate of December 1992February 1993. Part II: Large-scale variability across the tropical western Pacific during TOGA COARE. J. Climate, 7, 1606-1622.

Hendon, H. H., and M. L. Salby, 1994: The life cycle of the Madden-Julian oscillation. J. Atmos. Sci., 51, 2207-2219.

Hollinger, J. P., J. L. Peirce, and G. A. Poe, 1990: SSM/I instrument evaluation. IEEE Trans. Geosci. Remote Sens., 28, 781790.

Inness, P. M., and J. M. Slingo, 2003: Simulation of the MaddenJulian oscillation in a coupled general circulation model. Part I: Comparison with observations and an atmosphere-only GCM. J. Climate, 16, 345-364.

Johnson, R. H., T. M. Rickenbach, S. A. Rutledge, P. E. Ciesielski, and W. H. Schubert, 1999: Trimodal characteristics of tropical convection. J. Climate, 12, 2397-2418.

Jones, C., L. M. V. Carvalho, R. W. Higgins, D. E. Waliser, and J.-K. E. Schemm, 2004: A statistical forecast model of tropi- 
cal intraseasonal convective anomalies. J. Climate, 17, 20782095.

Kemball-Cook, S. R., and B. C. Weare, 2001: The onset of convection in the Madden-Julian oscillation. J. Climate, 14, 780793.

Kikuchi, K., and Y. N. Takayabu, 2004: The development of organized convection associated with the MJO during TOGA COARE IOP: Trimodal characteristics. Geophys. Res. Lett., 31, L10101, doi:10.1029/2004GL019601.

Lau, K.-M., and C.-H. Sui, 1997: Mechanisms of short-term sea surface temperature regulation: Observations during TOGA COARE. J. Climate, 10, 465-472.

Liebmann, B., and C. A. Smith, 1996: Description of a complete (interpolated) outgoing longwave radiation dataset. Bull. Amer. Meteor. Soc., 77, 1275-1277.

Lin, X., and R. H. Johnson, 1996: Kinematic and thermodynamic characteristics of the flow over the western Pacific warm pool during TOGA COARE. J. Atmos. Sci., 53, 695-715.

Liu, G., J. A. Curry, and R. S. Sheu, 1995: Classification of clouds over the western equatorial Pacific Ocean using combined infrared and microwave satellite data. J. Geophys. Res., 100, $13811-13826$.

Loschnigg, J., and P. J. Webster, 2000: A coupled oceanatmosphere system of SST regulation for the Indian Ocean. $J$. Climate, 13, 3342-3360.

Lukas, R., and E. J. Lindstrom, 1991: The mixed layer of the western equatorial Pacific Ocean. J. Geophys. Res., 96, $3343-$ 3357.

Madden, R. A., and P. R. Julian, 1972: Description of global-scale circulation cells in the tropics with a 40-50 day period. $J$. Atmos. Sci., 29, 1109-1123.

- , and - 1994: Observations of the 40-50-day tropical oscillation-A review. Mon. Wea. Rev., 122, 813-837.

Maloney, E., and D. Hartmann, 1998: Frictional moisture convergence in a composite life cycle of the Madden-Julian oscillation. J. Climate, 11, 2387-2403.

Simmons, A. J., and J. K. Gibson, 2000: The ERA-40 project plan. ECMWF ERA-40 Project Report Series 1, 62 pp.

Slingo, J. M., and Coauthors, 1996: Intraseasonal oscillations in 15 atmospheric general circulation models: Results from an AMIP diagnostic subproject. Climate Dyn., 12, 325-357.

Stephens, G. L., and Coauthors, 2002: The CloudSAT mission and the A-TRAIN. Bull. Amer. Meteor. Soc., 83, 1771-1790.

— - P. J. Webster, R. H. Johnson, R. Engelen, and T. L'Ecuyer, 2004: Observational evidence for the mutual regulation of the tropical hydrological cycle and tropical sea surface temperatures. J. Climate, 17, 2213-2224.

Terray, L., E. Sevault, E. Guilyardi, and O. Thual, 1995: OASIS 2.0, user's guide and reference manual. CERFACS Tech. Rep., TR/CMGC/95-46, 123 pp.

Vitart, F., 2004: Monthly forecasting at ECMWF. Mon. Wea. Rev., 132, 2761-2779.
Waliser, D. E., K. M. Lau, and J. H. Kim, 1999: The influence of coupled sea surface temperatures on the Madden-Julian oscillation: A model perturbation experiment. J. Atmos. Sci., 56, 333-358.

$\_,-$W. Stern, and C. Jones, 2003a: Potential predictability of the Madden-Julian oscillation. Bull. Amer. Meteor. Soc., 84, 33-50.

— , and Coauthors, 2003b: AGCM simulations of intraseasonal variability associated with the Asian summer monsoon. Climate Dyn., 21, 423-446.

Wang, B., and X. Xie, 1998: Coupled modes of the warm pool climate system. Part I: The role of air-sea interactions in maintaining Madden-Julian oscillation. J. Climate, 11, 21162135.

— , P. J. Webster, and H. Teng, 2005: Antecedents and selfinduction of active-break south Asian monsoon unraveled by satellites. Geophys. Res. Lett., 32, L04704, doi:10.1029/ 2004GL020996.

Wang, J., H. L. Cole, D. J. Carlson, E. R. Miller, K. Beierle, A. Paukkunen, and T. K. Laine, 2002: Corrections of humidity measurement errors from the Vaisala RS80 radiosondeApplication to TOGA COARE data. J. Atmos. Oceanic Technol., 19, 981-1002.

Webster, P. J., 1994: The role of hydrological processes in oceanatmosphere interaction. Rev. Geophys., 32, 427-476.

, and R. Lukas, 1992: TOGA-COARE: The Coupled OceanAtmosphere Response Experiment. Bull. Amer. Meteor. Soc., 73, 1377-1416.

- and C. Hoyos, 2004: Prediction of monsoon rainfall and river discharge on 15-30-day time scales. Bull. Amer. Meteor. Soc., 85, 1745-1765.

- , and Coauthors, 2002: The Joint Air-Sea Monsoon Interaction Experiment (JASMINE) pilot study. Bull. Amer. Meteor. Soc., 83, 1603-1630.

Weller, R. A., and S. P. Anderson, 1996: Surface meteorology and air-sea fluxes in the western equatorial Pacific warm pool during the TOGA Coupled Ocean Atmosphere Response Experiment. J. Climate, 9, 1959-1990.

Wheeler, M., and G. N. Kiladis, 1999: Convectively coupled equatorial waves: Analysis of clouds and temperature in the wavenumber-frequency domain. J. Atmos. Sci., 56, 374-399.

Wolff, J. E., E. Maier-Reimer, and S. Legutzke, 1997: The Hamburg ocean primitive equation model. Deutsches Klimarechenznetrum Tech. Rep. 13, 98 pp.

Woolnough, S. J., J. M. Slingo, and B. J. Hoskins, 2000: The relationship between convection and sea surface temperature on intraseasonal timescales. J. Climate, 13, 2086-2104.

Zhang, C., 2005: Madden-Julian Oscillation. Rev. Geophys., 43, RG2003, doi:10.1029/2004RG000158.

— and M. J. McPhaden, 2000: Intraseasonal surface cooling in the equatorial western Pacific. J. Climate, 13, 2261-2276. 
Copyright of Journal of Climate is the property of American Meteorological Society and its content may not be copied or emailed to multiple sites or posted to a listserv without the copyright holder's express written permission. However, users may print, download, or email articles for individual use. 